lead to the penetration of charged particles into the mesosphere in the polar regions of the Earth (solar proton or PCA events). These charged particles cause the dissociation of water vapour to create atomic hydrogen and hydroxyl radicals which catalytically destroy ozone. At lower levels the charged particles create oxides of nitrogen from the molecular nitrogen and molecular oxygen of the atmosphere. If a significant number of solar proton events occur during the operational lifetime of the $\mathrm{SME}$, the instruments will be used to determine the relationship between the magnitude of decrease in ozone and the flux and energy of the solar protons and the role of water vapour in the solar proton destruction of ozone.
*The orbit of SME is planned to be circular at an altitude of 540 $\mathrm{km}$ and sun-synchronous with the Equator crossing occurring at 3 p.m. local time. The four limb-scanning instruments will view the atmosphere in the plane of the orbit. The satellite will be operated from a control center at the Laboratory for Atmospheric and Space Physics, University of Colorado, Aoulder. ThE Boulder. The SME investigator team consists of scientists from Department of Astro-Geophysics of the University of Colorado, the National Center for Atmospheric Research, the National Oceanic and Atmospheric Administration Aeronomy Laboratory and the Jet Propulsion Laboratory. The mission is a NASA project, managed by the Jet Propulsion Laboratory.

\title{
The significance of unique or rare meteorites
}

\section{from Robert Hutchison}

Most meteorites have chemical properties which place them in one of 27 groups, each containing five or more members. Much of our knowledge of the chemistry and early history of planetary bodies in the Solar System is based on these common types of meteorite, but it is the rarities which often provide data vital to planetary science. A prime example is the Angra dos Reis (stone) meteorite which fell into $2 \mathrm{~m}$ of seawater in Brasil in 1869. Two pieces, together weighing approximately $1.5 \mathrm{~kg}$, were recovered by a diver the day after its fall. The importance of the meteorite is such that a consortium was set up to study it in the mid $1970 \mathrm{~s}^{1}$.

The detailed petrographical and mineralogical work of Prinz and colleagues showed the meteorite to be a cumulate of exceptionally Ca-rich pyroxene crystals. In addition, their analyses confirmed the earlier conclusion of Hutchison ${ }^{2}$ that the mineral assemblage is indicative of a high degree of silica undersaturation. Ma and co-workers calculated from the trace element content of the bulk meteorite and of mineral separates that the meteorite represents a late stage in the fractional crystallization of a liquid which formed as a partial melt from an olivine-orthopyroxene-clinopyroxene source. This, however, poses a problem, for production of an undersaturated liquid from orthopyroxene-bearing starting material requires a pressure $>7 \mathrm{kbar}$, and hence a lunar-sized parent planet. Various rare gas, isotopic and fission-track studies indicate that Angra dos Reis (stone) crystallized close to 4.55 Gyr ago and cooled faster than $70 \mathrm{~K} \mathrm{Myr}{ }^{1}$. This age is within experimental error of that of the eucrites (see, for example, ref.3), basaltic meteorites which crystallized from tholeiitic liquids ${ }^{4}$. Thus, both saturated and undersaturated silicate liquids were extant at about the same time, an observation consistent with the coexistence of orthopyroxene-bearing and nepheline-normative chondrules in unequilibrated ordinary chondrites (see,

Robert Hutchison is at the British Museum (Natural History), where he is in charge of the National Collection of Meteorites. for example, refs 5,6). Angra dos Reis (stone) raises the question of whether lunar-sized objects may be represented in meteorite collections. Other possibilities are that silica-undersaturated planetesimals existed, or a non-magmatic process, such as vapour fractionation (loss) of silica, may have taken place.

At the other extreme from Angra dos Reis (stone), but equally problematical, are Nakhla and two similar meteorites. Nakhla is a meteorite shower which fell in Egypt in 1911 and comprises an unshocked, coarsegrained pyroxene-olivine cumulate (see ref. 7 and refs therein) with a crystallization age of $1.24 \mathrm{Gyr}^{8}$. Samarium-neodymium systematics are consistent with the age of $1.24 \mathrm{Gyr}$, but they also indicate that the parent material had a three (or more)-stage fractionation history if a chondritic composition is assumed for the original source ${ }^{9}$. The complete resetting of the Sm$\mathrm{Nd}$ 'clock' means that the igneous event caused the efficient separation of a light rare earth element-enriched liquid from a crystalline residue. This is unlikely to have been achieved by transient heating following impact and hence points to volcanism on a planetary body only 1.24 Gyr ago. The environment was oxidizing and hydrous ${ }^{10}$, so Mars is a possibility. However, the absence of shock features in the Nakhlites renders it unlikely that they could have been accelerated to the escape velocity of Mars, some $5 \mathrm{~km} \mathrm{~s}^{-1}$. In contrast, the rare meteorites known as shergottites were shocked about $200 \mathrm{Myr}$ ago, although their magmatic crystallization ages are somewhat older ${ }^{11}$. Thus a martian origin is just conceivable for the shergottites.

Finally, let us turn to the origin of iron meteorites. About 86 per cent of irons belong to one of 12 chemical groups, the remainder being distributed among 'grouplets' each comprising one to four members. Scott has argued that the chemical composition of an iron was determined first by nebular condensation to form the parent body, then by crystalliquid fractionation. In all, some 60 parent planetesimals may be represented among our meteorite collections.
More recently, Scott ${ }^{12}$ takes into consideration cosmic-ray exposure ages, cooling rates of the irons and the probability of sampling asteroids. The exposure ages ${ }^{13}$ indicate that iron meteorites were randomly released as small objects from their parent planets from 50 to $1,400 \mathrm{Myr}$ ago, except for members of groups IIIAB and IVA, which were mostly released in two events 650 and $400 \mathrm{Myr}$ ago respectively. Such events are probably rare, and so it seems unlikely that many asteroids could have been involved in major collisions which produced potential meteorites. One possibility considered by Scott is that some of the parent asteroids are composite, each being comprised of a number of smaller planetary bodies which had individually differentiated into metallic core and silicate mantle before incorporation into the larger body.

There is, in fact, evidence to suggest that this was the case. Axon and Bevan ${ }^{14}$ interpreted the structure of the Jamestown (IVA) iron as the result of a pre-terrestrial, crater-forming impact on an unknown planetesimal. The irons of group IVA often are shocked and they have a wide range of cooling rates. These observations would be consistent with a history of formation in one planetesimal followed by incorporation into a second, larger body.

So, from information derived from rare or unique meteorites, we can conclude that we may have samples from an ancient, lunar-sized object, from Mars, and from composite asteroids.

\footnotetext{
1. Keil, K. et al. Earth planet. Sci. Lett. 35, 271 (1977).

2. Hutchison, R. Nature phys. Sci. 240, 58 (1972)

3. Hamet, J. et al. Proc. 9th Lunar planet. Sci. Conf. 115 (1978)

Stolter, E. Geochim. cosmochim. Acta 41, 587 (1977).

5. Dodd, R.T. Earth planet. Sci. Lett. 40, 71 (1978).

6. Hutchison, R, et al. Nature 280, 116 (1979).

7. Berkley, J.L. et al. Proc. 11th Lunar planet. Sci. Conf Berkley, J.L. et al. Proc. 11th Lunar planet. Sci.
1089 (1980).

8. Gale, N.H. Earth planet. Sci. Lett. 26, 195 (1975). 701, 305 (1978).

10. Ashworth, I R \& Hutchison, R. Nature 256, 714 (1975)

11. Meteoritics 14 (1979); Bogard, D.D. p.356; Nyquist, L.E et al., p.502.

12. Scott in Asteroids (ed. Gehrels, T.) 892 (University of Arizona Press, 1979)

13. Bogard, D.D. in Asteroids (ed. Gehrels, T.) 558 (University of Arizona Press, 1979).

14. Axon, H.J. \& Bevan, A.W.R. Nature 263, 302 (1976).
} 